\title{
ÉTICA NA ADVOCACIA E MUNDO DIGITAL: DESAFIOS PARA O ADVOGADO 4.0
}

\section{ADVOCACY ETHICS AND THE DIGITAL WORLD: CHALLENGES FOR LAWYER 4.0}

Max Xaveir Rocinholi

Luiz Roberto Prandi²

${ }^{1}$ Direito pela Universidade Paranaense - UNIPAR Umuarama - Paraná. maxrocinholi@gmail.com

2 Doutor em Ciências da Educação, Mestre em Ciências da Educação, Especialista em Gestão e Educação Ambiental, Metodologia do Ensino Superior, Docência do Ensino Superior, Gestão de Políticas Sociais, Gênero, Diversidade no Espaço Escolar, Análise Criminal, Direito Educacional e Pedagogia Sistêmica, Autor de Livros, Pesquisador e Professor Titular da Universidade Paranaense UNIPAR - Umuarama - Paraná. E-mail: prandi@ prof.unipar.br.
ROCINHOLI, M. X.; PRANDI, L. R. Ética na advocacia e mundo digital: desafios para o advogado 4.0. Akrópolis, Umuarama, v. 29, n. 1, p. 127-136, jan./jun. 2021.

\section{DOI: https://doi.org/10.25110/akropolis.v29i1.8487}

Resumo: O respectivo artigo buscará levantar questionamentos a respeito da atuação do advogado nos meios digitais e suas implicações em relação ao Código de Ética e Disciplina da OAB (Resolução CFOAB n. ${ }^{\circ}$ 02/2015) e ao Estatuto da categoria (Lei n. $\left.{ }^{\circ} 8906 / 94\right)$. Tais mecanismos servem como parâmetro ético e norteiam a atividade advocatícia. Nesse sentido, investigar-se-á os principais mecanismos utilizados pelos advogados no campo digital, arrazoando suas implicações na esfera ética de tal profissão. De plano, serão analisadas a validade do impulsionamento pago de publicações em redes sociais e a participação do advogado em plataformas de cadastro, divulgação e angariação de clientela. Num segundo momento, buscou-se a jurisprudência do Ementário da OAB Paraná, para os resultados da pesquisa "publicidade", com ênfase nos meios digitais. Estabelecendo ao final uma conclusão sobre o que se entende salutar para o bom exercício da advocacia digital.

Palavras-chave: Código de ética e Disciplina da OAB; Advocacia digital; Limites éticos; Estatuto da OAB; Tribunal de ética e Disciplina da OAB Paraná.

ABSTRACT: This article seeks to raise questions about the work of lawyers in digital media and its implications in relation to the $O A B$ (Brazilian Bar Association) Code of Ethics and Discipline (CFOAB Resolution No. 02/2015) and the OAB Statute (Law No. 8906/94). Such mechanisms are used as ethical parameters and as such, guide the advocacy activity. Therefore, this study will investigate the main mechanisms used by lawyers in the digital field, presenting its implications in the ethical sphere of the profession. Thus, it analyzed the ethical validity of paid publications (advertisement) on social media and the lawyer's participation in platforms of registration, advertising, and acquisition of clients. Secondly, it analyzed the jurisprudence of the $O A B$ from the state of Paraná, for the results of the search for "advertisement" with focus on digital media. It concludes by establishing what is meant to be healthy for the good exercise of digital advocacy.

KeYwords: OAB Code of Ethics and Discipline; Digital advocacy; Ethical limits; OAB Statute; OAB Paraná Court of Ethics and Discipline. 


\section{INTRODUÇÃO}

Tendo como base a Ética do Advogado, prescrita no Código de Ética e Disciplina da OAB (CED) e no Estatuto da mesma entidade, esta pesquisa visa a contribuir para o estudo das questões mais recentes ligadas ao exercício ético da advocacia no mundo digital.

Este estudo buscou analisar o alcance e efetividade das prescrições do Código de Ética da $\mathrm{OAB}$ em relação à atuação do advogado no meio digital, identificando quais os desafios e limites para a atuação ética do advogado por meio da utilização de novas plataformas digitais, verificando quais as inovações utilizadas comumente.

O modo como atua o advogado, pautandose pela ética ou por caminhos distintos deste, influenciam no corpo social como um todo. Analisar as normas reguladoras da categoria, em contraponto a necessidade e adequação as novas plataformas disponíveis a classe é propor um estudo altamente relevante do ponto de vista social e jurídico.

É inegável que as profissões e, por conseguinte, 0 agir dos profissionais careçam de atualização de tempos em tempos, a fim de acompanhar as mudanças sociais, tecnológicas, culturais etc. As relações sociais do homem moderno tomam novos contornos a partir dos avanços tecnológicos que permeiam o cotidiano. Nesse diapasão, a advocacia vem se inovando e buscando alternativas para acompanhar tal evolução.

Entretanto, algumas condutas modernas podem implicar na violação ao CED ou, por vezes, apresentar situações deontologicamente insanáveis ou de pouco amparo com base nos mandamentos contidos no referido Código. Uma das maiores apostas dos escritórios e advogados em geral, está nas redes sociais e nas demais plataformas via internet, disponibilizando seus serviços e interagindo com um maior número de pessoas.

Apesar de tal tendência ser extremamente atrativa, para os advogados e sociedades de advogados, há restrições que implicam em uma conduta mais comedida, tergiversando o que se pratica no mercado digital. O Código de Ética e Disciplina da Ordem dos Advogados do Brasil $\mathrm{OAB}$, restringe de modo taxativo algumas práticas relacionadas à publicidade, visando com isto vedar a mercantilização da profissão.
Assim, até que ponto tal restrição é favorável à classe? Sendo a internet um meio tão disseminado de informações e um campo aberto ao empreendedorismo, quais princípios deontológicos devem orientar o advogado que se utiliza desses meios?

O Código de Ética e Disciplina da OAB, com suas imposições éticas consegue inibir tais práticas violadoras? Poder-se-ia questionar, ainda, quais práticas de fato são proibidas e quais os limites que balizam a conduta do advogado na rede mundial de computadores?

O CED e o EAOAB, além de limitarem a atuação também não deixam claro algumas questões importantes, por exemplo: o Código de Ética veda a veiculação de publicidade profissional em rádio, cinema, TV, outdoors, painéis luminosos ou formas assemelhadas de publicidade. Porém, em um cotidiano onde grande parte dos indivíduos passa o dia navegando na internet ou nas redes sociais, seria mais fácil de ser visualizada uma publicação em uma rede social como o facebook, ao invés de um outdoor colocado em um ponto fixo pela cidade.

Ainda que o caráter seja meramente informativo, conforme prevê o código de ética, a publicação patrocinada, pela qual se possibilita escolher inclusive a faixa etária do público a atingir, não seria uma forma de captação e publicidade que violaria o Código de Ética da OAB? Indagações como essa ainda não possuem uma resposta convincente e adequada.

Tratando-se de tema recente e com pouca bibliografia a respeito, o presente projeto buscará estabelecer um referencial teórico da temática e sua jurisprudência correlata. Para a realização desses propósitos escolheu-se a metodologia de pesquisa cuja natureza encontra respaldo em métodos apropriados para o tema de ordem social, dentre os quais, se revela a pesquisa bibliográfica e documental de temas correlatos e decisões proferidas pelos Tribunais de Ética e Disciplina da $\mathrm{OAB}$, bem como do Conselho Federal.

Nesse sentido, o estudo ora apresentado buscará embasamento em uma análise descritiva com abordagem qualitativa das decisões e do parâmetro que esposou tais pronunciamentos.

\section{ADVOGADO 4.0}

O advento da era digital influenciou e 
continua influenciando a vida humana como um todo. Dado o desenvolvimento tecnológico, de um modo geral todos os profissionais foram impactados e forçados a se readequarem ao uso dessas novas ferramentas disponíveis.

Profissões tradicionais passaram a interagir e utilizar plataformas digitais a seu favor, e com a advocacia não foi diferente. Com o advento de tais mecanismos surgiram expressões como "advogado 4.0", para denominar o perfil de advogado alinhado às novidades tecnológicas.

A quarta revolução industrial, ou Indústria 4.0 , é um conceito desenvolvido pelo alemão Klaus Schwab, fundador e presidente executivo do Fórum Econômico Mundial em seu livro "A quarta revolução industrial".

Essa revolução industrial não é definida por um conjunto de tecnologias emergentes em si mesmas, mas sim da transição em direção a novos sistemas que foram construídos sobre a infraestrutura da revolução digital. As tecnologias englobadas nesse contexto da Indústria 4.0 não estão restritas aos universos da nanotecnologia, neurotecnologia, biotecnologia, robótica, inteligência artificial e armazenamento de energia. (SCHWAB, 2016).

Desta acepção de quarta revolução industrial, denomina-se "advogado 4.0" o profissional alinhado à inserção dessas ferramentas à prática advocatícia, havendo ampla menção ao termo no meio jurídico.

Apesar de processadores, plataformas inovadoras e programas contribuírem para a otimização dos processos e realizarem em segundos atividades que demorariam horas, a atividade advocatícia não pode se afastar dos princípios deontológicos basilares.

Neste sentido, todas as ações exercidas pelo advogado deve haver a observância dos princípios éticos intuídos no código profissional, uma vez que é exclusivo do advogado o jus postulandi, ou seja, cabe ao advogado estabelecer a conexão entre o poder judiciário e a sociedade, salvo exceções pontuais de interesses de pequena monta, onde o cidadão pode postular diretamente nos juizados.

O artigo $1^{\circ}$ da Lei 8.906/94 determina que: "São atividades privativas de advocacia: postulação a órgão do Poder Judiciário e aos juizados especiais". Ademais, a própria Constituição Federal de 1988, em seu art. 133, estabelece que: "O advogado é indispensável à administração da justiça, sendo inviolável por seus atos e manifestações no exercício da profissão, nos limites da lei". Dada à importância deste profissional, exige-se uma atuação ética com a observância desta e de outras prerrogativas.

Tal pudor em preservar a advocacia de uma publicidade mercantilista, que banalizasse a profissão, obrigou o Conselho Federal da OAB a abordar a publicidade nos meios digitais em seu CED, em 2015. No entanto, as normativas estabelecidas, ao que indica o quadro geral da prática advocatícia, não têm sido suficientes para inibir ou punir de maneira verdadeiramente pedagógica as violações por meio da internet.

\section{3. ÉTICA PROFISSIONAL E PUBLICAÇÕES IMPULSIONADAS}

Considerando a falibilidade do ser humano em manter uma conduta tida socialmente como adequada e que preserve a dignidade da classe e da própria profissão, faz-se necessário estabelecer limites comportamentais à sua atuação.

Por essa razão o Código de Ética e Disciplina da $O A B$, em seu art. $1^{\circ}$ invoca uma conduta ética: "[...] com os princípios da moral individual, social e profissional". Assim, a ética profissional presta-se a referendar normas, condutas e procedimentos tidos como adequados ou mais caros à determinada profissão. Na acertada pontuação do que vem a ser ética profissional, Vieira e Martins (2007, p. 18) discorrem:

\footnotetext{
Ética profissional é o conjunto de princípios e regras que regem a conduta de determinada profissão, considerando suas particularidades. Trata-se de um padrão de comportamento que se torna (moral e legalmente) imprescindível a quem deseja desempenhar tal ofício, seja em relação aos demais colegas, aos clientes, à sociedade e, inclusive, a si próprio.
}

A fim de manter uma coerência temporal e acompanhar as inovações do corpo social, a lei deve ser atualizada sempre que necessário. Nesta baila, quando o assunto é a ética profissional, esta, ainda que de modo tímido, carece de renovação periódica para um ajuste de diretrizes. Nas palavras de Couture (1979, p. 9-10), eternizado por seu decálogo sobre os deveres éticos do advogado: 
Aadvocacia e as formas de seu exercício são experiências históricas. Suas necessidades e também seus ideais transformam-se com o decorrer do tempo e novas exigências vão surgindo ante o espírito do homem. Por esta razão, é necessário repensar periodicamente os mandamentos para ajustá-los às novas realidades.

Ante o avanço tecnológico das mídias, a reformulação do CED em 2015 buscou atingir um novo patamar em relação às inovações no mundo da advocacia. Entretanto, tais foram alterações modestas, abarcando pouquíssimas situações, contrapondo assim o modelo atual da advocacia.

Considerando o marketing digital, que será explorado adiante, é mais que uma realidade, o fato do novo código utilizar a palavra "internet" apenas três vezes de modo tímido (arts. 40 , inc. $\mathrm{V}$ e 46 , caput e parágrafo único), configura-se como algo muito aquém do esperado para a atualidade.

Inobstante a explanação supra, não se ignora, aqui, um dos pilares da norma jurídica que é a sua abstratividade. Tal elemento permite à norma alcançar inúmeras situações sem que necessariamente careça de reformulações no tempo - cabendo destacar: norma posterior traria igualmente o caráter abstrato. Kelsen (1999, p. 247) Grifo nosso, ressalta o modo interpretativo da norma em razão do objeto analisado e o seu alcance em sentido criativo:

Se por interpretação se entende a fixação por via cognoscitiva do sentido do objeto a interpretar, o resultado de uma interpretação jurídica somente pode ser a fixação da moldura que representa o Direito a interpretar e, consequentemente, o conhecimento das várias possibilidades que dentro desta moldura existem. Sendo assim, a interpretação de uma lei não deve necessariamente conduzir a uma única solução como sendo a única correta, mas possivelmente a várias soluções que - na medida em que apenas sejam aferidas pela lei a aplicar - têm igual valor, se bem que apenas uma delas se torne Direito positivo no ato do órgão aplicador do Direito - no ato do tribunal, especialmente. Dizer que uma sentença judicial é fundada na lei, não significa, na verdade, senão que ela se contém dentro da moldura ou quadro que a lei representa - não significa que ela é a norma individual, mas apenas que é uma das normas individuais que podem ser produzidas dentro da moldura da norma geral.

Como delineado, as prerrogativas éticas do profissional da advocacia estão ligadas direta ou indiretamente aos fins sociais e institucionais do Estado, numa conexão entre a sociedade e a jurisdição estatal como um todo. Desse modo, o código poderia ter inovado com maior apreço questões relacionadas à atuação virtual dos advogados.

Entre os baluartes do novo marketing digital realizado pelo advogado 4.0, estão o dinamismo e as peculiaridades da utilização de softwares e redes sociais, para os quais o Código encontra-se omisso deontologicamente.

É oportuno ressaltar ainda, que os profissionais que cometam atos contrários aos mandamentos disciplinares do CED, estarão sujeitos ao processo ético-disciplinar, regulado pelo Estatuto da OAB em seus artigos 70 a 74 .

Uma das motivações que justifica e norteia o presente estudo, é a análise do entendimento jurisprudencial dos Tribunais de Ética e Disciplina (TED) da OAB, uma vez que tais mecanismos possibilitam verificar a configuração ou não de determinadas condutas em redes sociais e a eficácia e abrangência do CED.

Por exemplo, em relação à análise das publicidades veiculadas por advogados no Facebook, o relator da Primeira Turma de Ética Profissional da OAB/SP concluiu que as informações podem ser publicadas neste tipo de plataforma, desde que mantenham o cunho objetivo e informativo e não possuam a finalidade de angariar clientela:

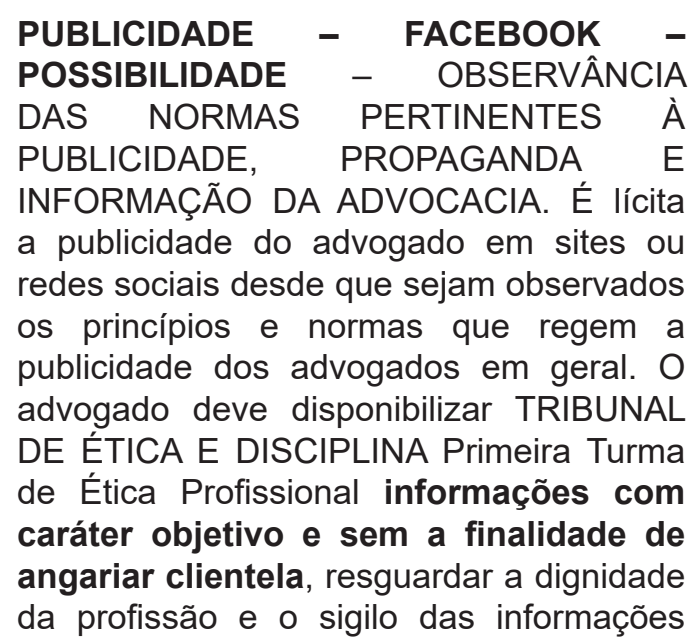


que lhe foram confiadas por seus clientes e respeitar os limites e condições impostos pelo Estatuto da Advocacia, pelo Código de Ética e Disciplina, bem como pelo Provimento $n^{\circ}$ 94/2000 do Conselho Federal da OAB. Precedentes. Proc. E4.484/2015 v.m., em 19/03/2015, do parecer e ementa do Rel. Dr. FÁBIO TEIXEIRA OZI - Rev. Dr. FABIO KALIL VILELA LEITE - Presidente Dr. CARLOS JOSÉ SANTOS DA SILVA.

No caso supracitado, vê-se a aplicação cristalina das disposições do artigo $5^{\circ}$ e 39 do CED, que especificam que:

Art. $5^{\circ} \mathrm{O}$ exercício da advocacia é incompatível com qualquer procedimento de mercantilização. Art. 39. A publicidade profissional do advogado tem caráter meramente informativo e deve primar pela discrição e sobriedade, não podendo configurar captação de clientela ou mercantilização da profissão. Grifei. (CFOAB, 2015).

Para além da interpretação literal dos artigos, conforme exposto, deve-se também questionar qual o posicionamento das Turmas de Ética e Disciplina da OAB em relação as questões mais complexas como, por exemplo, o patrocínio de publicações em redes sociais. Segundo o relatório Digital in 2017 (online), em 2017 58\% da população brasileira utilizou redes sociais. A pesquisa revela, ainda, que a rede social Facebook contabiliza 130 milhões de usuários no Brasil.

Ao publicar um texto, foto ou anexo no Facebook, o usuário pode patrocinar esta publicação. Esse fomento serve para impulsionar a postagem, fazendo com que mais pessoas possam ver a publicação. Na rede social referida, pode-se eleger cumulativamente as seguintes características ao impulsionar uma publicação:

1) Faixa etária; 2) Região de abrangência; 3) Refinamento de público para alcançar pessoas que sejam relevantes para o divulgador; 4) Incentivar pessoas a visitarem o site do divulgador; 5) Duração do direcionamento; e 6) Pessoas que curtiram a página do divulgador ou, amigos destes amigos. (FACEBOOK, documentos digitais).
Inobstante tamanhas facilidades e mecanismos, pode-se visualizar uma estimativa de alcance. Iniciando-se num mínimo de 2.600 usuários, 13.000 por dia. Até um limite de 4.700.000 pessoas. Tudo isso a partir de 6,00 U\$D (seis dólares) diários. De modo contrário a tal publicidade excessiva, o CED em seu artigo 40 veda condutas tidas como incompatíveis com a publicidade profissional do advogado:

I - a veiculação da publicidade por meio de rádio, cinema e televisão; II - o uso de outdoors, painéis luminosos ou formas assemelhadas de publicidade; III - as inscrições em muros, paredes, veículos, elevadores ou em qualquer espaço público; IV - a divulgação de serviços de advocacia juntamente com a de outras atividades ou a indicação de vínculos entre uns e outras; $\mathrm{V}$ - o fornecimento de dados de contato, como endereço e telefone, em colunas ou artigos literários, culturais, acadêmicos ou jurídicos, publicados na imprensa, bem assim quando de eventual participação em programas de rádio ou televisão, ou em veiculação de matérias pela internet, sendo permitida a referência a e-mail; $\mathrm{VI}$ - a utilização de mala direta, a distribuição de panfletos ou formas assemelhadas de publicidade, com o intuito de captação de clientela. (CFOAB, 2015) grifo nosso.

Numa análise prévia do artigo supracitado, as principais restrições ao modo de marketing jurídico do CED são modestas, para não dizer obsoletas. Ainda, em seu artigo 46 o Código ao tratar a respeito da publicidade digital esclarece que:

A publicidade veiculada pela internet ou por outros meios eletrônicos deverá observar as diretrizes estabelecidas neste capítulo. Parágrafo único. A telefonia e a internet podem ser utilizadas como veículo de publicidade, inclusive para o envio de mensagens a destinatários certos, desde que estas não impliquem o oferecimento de serviços ou representem forma de captação de clientela. (CFOARB, 2015) Grifo nosso.

Pelo exposto até aqui, vê-se que o Código profissional dos advogados priva a publicidade em muros, outdoors, porém a utilização de ferramentas 
e mídias digitais como o Facebook, possibilitam uma publicidade com um impacto muito maior do que aquelas vedadas pelo Código. Desse modo, deve-se analisar até que ponto o uso de tais aparatos digitais não se tornam mais danosos ao exercício da advocacia contemporânea do que aqueles vedados de modo explícito pelo código. Segundo Azevedo, et al. (2018, p. 321):

A principal preocupação na regulamentação deontológica da publicidade se dá por conta da incompatibilidade da advocacia com a mercantilização, conforme visto quando da análise do artigo $5 .^{\circ}$. Assim, a publicidade na advocacia é alvo de diversas restrições que possuem a exata finalidade de impedir a mercantilização da advocacia por meio da utilização de publicidade como forma de captação de clientela.

Com base nos autores, pode-se dizer, em caráter precário, que o Código de Ética e Disciplina da $O A B$ necessita de um maior refinamento nos assuntos que envolvam a utilização de mecanismos digitais, sendo necessário, ainda, que os Tribunais de Ética e Disciplina se atualizem com as novas proposições do marketing digital. Questões estas que são salutares e atuais, mas ainda pouco exploradas cientificamente.

Divulgar produtos e serviços nas redes sociais é inegavelmente uma forma de expandir negócios e angariar novos clientes, negócios, enfim, crescer no mercado desejado. Contudo, o advogado 4.0, apesar de inserido neste contexto, não pode se deixar levar pela tentação e o deslumbre, ante a consideração dos parâmetros éticos e legais que norteiam suas ações. Se por um lado, aparenta ser um bom negócio a publicidade na internet, por outro, tem-se o risco de violar seriamente as condutas éticas reservadas à classe.

Em 2015, o CED da OAB foi alterado, na busca por uma atualização, que, no entanto, mostrou-se obsoleta, já que não abordou de forma específica e objetiva as questões relacionadas à participação do advogado na internet, sobretudo nas redes sociais. Comprova essa obsolescência o fato da palavra internet constar apenas três vezes em todo seu texto.

Os princípios norteadores da atividade jurídica possuem pilares que fundamentam tais restrições, sejam com previsão constitucional ou infraconstitucional, conforme apresentado neste trabalho.

Nesse sentido, a atuação do advogado está diretamente relacionada ao interesse público e cumprimento da lei, em paralelo à finalidade do processo jurídico - a justiça. Isto é, a atividade do advogado não visa, ou pelo menos não deveria visar de forma primária, interesses financeiros particulares. É assim que entende o Conselho Federal da OAB:

O advogado é essencial à função jurisdicional do Estado, prestando serviço público e exercendo função social em seu ministério privado, conferindo-se aos membros do Poder Judiciário e órgãos do Ministério Público a legitimidade para velar pelo exercício probo da advocacia. Alegação de violação ao princípio da presunção de inocência. Inexistência. Tal princípio não pode ser invocado para buscar assegurar impunidade pelas infrações nitidamente caracterizadas nos autos. Recurso conhecido e improvido. (RECURSO 49.0000.2011.001471-7/SCASTU, EMENTA 054/2012/SCA-STU, Rel. Walter Carlos Seyfferth, DOU. 16/05/2012).

Nesse cenário, o exercício do advogado não pode confundir-se com a atividade mercantil, e é nesse sentido que o Art. $4^{\circ}$ do provimento $n^{\circ}$ 94/2000 do Conselho Federal da OAB dispõe: "Não são permitidos ao advogado em qualquer publicidade relativa à advocacia: [...] I) utilização de meios promocionais típicos de atividade mercantil". Isso, entretanto, não denota que o advogado está impedido de usufruir da publicidade a seu favor, o marketing jurídico é legítimo desde que obedeça os parâmetros e as restrições legais.

O marketing digital está em alta e a tendência mundial é de que esses números continuem a subir. Relatório publicado pela Marketing Land (2019, online) mostrou que o gasto com anúncios do Facebook em 2019 cresceu 40\% em relação ao segundo trimestre de 2018, e os investimentos em anúncios no Instagram aumentaram $177 \%$ durante o mesmo período. No Brasil, há uma previsão de aumento de $12 \%$ até 2021 com investimento em marketing digital, aponta pesquisa publicada pela revista Exame.

Os dados demonstram a relevância que o meio digital desempenha no mundo dos negócios. Estar alinhado a essa tendência pode ser uma ótima oportunidade para crescer enquanto advogado ou 
sociedade de advogados, sem perder a sobriedade e moderação.

\section{PLATAFORMA PAGA DE INTERAÇÃo CLIENTE ADVOGADO}

Visando ao público jurídico, alguns sites tornaram-se plataformas direcionadas ao recrutamento de advogados para disponibilização de seus serviços online. Tais sites formam uma espécie de diretório de advogados com diversos profissionais cadastrados, fornecendo contato e até mesmo consultoria jurídica.

Em poucos cliques, um possível cliente de demanda judicial pode entrar em contato com um dos advogados cadastrados no site. Levando em consideração o fato do interessado em sanar dúvida jurídica ou mesmo ingressar com ação judicial procurar online um profissional para auxiliálo não parece ser eivado de qualquer violação aos preceitos éticos amplamente abordados neste artigo. Porém, trata-se de praticidade e evolução da atividade ou captação de clientela?

\subsection{PAGANDO (AO INVÉS DE RECEBER) PARA PRESTAR SERVIÇOS PRIVATIVOS DA ADVOCACIA}

Segundo o estatuto da advocacia, a consultoria jurídica é atividade privativa do advogado, art. $1^{\circ}$, inciso II da Lei 8906/1994. Em decorrência da exclusividade, a Ordem dos Advogados do Brasil estabelece parâmetros para a prestação do serviço, sendo este variável de acordo com a realidade de cada estado do país.

A tabela que estabelece os valores tidos como dignos ao exercício da advocacia, no Estado do Paraná, foi atualizada pela Resolução do Conselho Seccional $n^{\circ} 20$ de 07/12/2018. Nela, consta a recomendação de preços para consulta, nos seguintes termos: "Consulta/Reunião: 1.1. No escritório pessoalmente, por telefone ou qualquermeio eletrônico: $\mathrm{R} \$ 350,00$ (trezentos e cinquenta reais); 1.2. Externa (local distinto do escritório - valor por hora ou fração): $R \$ 405,00$ (quatrocentos e cinco reais)". (OAB/PR 2019).

A razão de existência da tabela de preços citada no tópico anterior reflete a recomendação do órgão de classe quanto à valorização dos membros desta. Não sendo uma norma de caráter coercitivo, pode haver variações nos valores efetivamente cobrados pelos profissionais no momento da consulta, mas deve-se cobrar por ela.

Ocorre que na hipótese de vinculação do advogado junto a plataforma a ordem natural das coisas se perde. Todo esforço de valorização supracitado inexiste. O advogado ao invés de receber pela prestação de seu serviço, passa a pagar mensalmente ao site um plano de assinatura de créditos para obter maior visibilidade e acesso aos possíveis clientes.

Neste caso, os clientes em potencial depositam suas dúvidas na plataforma, e o advogado cadastrado, pode ou não respondê-las. Caso opte por responder, pagará uma taxa a qual será descontada de seus créditos contratados.

O artigo 41 do CED prevê que "as colunas que o advogado mantiver nos meios de comunicação social ou os textos que por meio deles divulgar não deverão induzir o leitor a litigar nem promover, dessa forma, captação de clientela" (CFOAB, 2015). Tal dispositivo invalida a prática utilizada pela plataforma para angariar advogados e fomentar a comunicação destes a pessoas leigas interessadas em seus serviços.

Nessa acepção, os sites além de mercantilizarem a profissão, estimulam a judicialização das controvérsias. Quanto mais alto o valor pago, maior a possibilidade de realizar atendimentos via plataforma. Ou seja: atividade reconhecidamente mercantil, com a plataforma lucrando sobre a consultoria prestada pelo advogado, algo que não se parece com as prescrições já elencadas neste trabalho.

Segundo o doutrinador Paulo Lôbo (2012, p. 21): "A assessoria jurídica [...] se perfaz auxiliando quem deve tomar decisões. [...] A consultoria jurídica não pode ser prestada como oferta ao público". Tendo em vista tal afirmação, pode-se inferir o não cabimento da atividade realizada pela plataforma online para, travestida de diretório antigas páginas amarelas das listas telefônicas.

Nesse rol de sites que disponibilizam contatos jurídicos, a mera veiculação dos dados pessoais e profissionais do advogado não caracteriza violação aos códigos. A objeção está contida no fato de haver pagamentos por parte do advogado para que receba dúvidas de possíveis clientes - o que é nítida captação de clientela.

O Estatuto da Advocacia e da OAB, Lei $n^{\circ}$ $8.906 / 94$, dispõe no parágrafo primeiro do art. $2^{\circ}$ [...] que "em seu ministério privado, o advogado 
presta serviço público e exerce função social”. Se a justificativa das plataformas é o acesso à justiça, respeito ao papel relevante exercido pelo advogado, não caberia tal função ao Conselho Nacional de Justiça e a Ordem dos Advogados do Brasil criarem um sistema online semelhante?

No meio físico, é sabido que a $O A B$ disponibiliza nas subseções e seccionais um escritório compartilhado, onde o advogado consegue agendar e atender seus clientes. Acompanhado a evolução das mídias, poderia fomentar mecanismos para que seus inscritos tivessem interação online mais próxima à população, sem precisar pagar um valor mensal para ter acesso a esse nicho de clientes e de forma a não estimular a mercantilização da advocacia ou mesmo sua banalização.

\section{ANÁLISE JURISPRUDENCIAL DO TED DA OAB PARANÁ SOBRE USO DE FERRAMENTAS DIGITAIS}

Ante as práticas publicitárias de interação do advogado no mundo digital descritas até aqui, desde impulsionamento de publicações em redes sociais até a participação em plataformas que fomentam a captação de clientela, faz-se necessária à análise quanto às punições impostas aos que pratiquem infrações éticas quanto ao tema.

Quando à infração é noticiada ao Conselho Seccional, instaura-se o processo disciplinar na localidade onde o advogado mantenha inscrição, salvo se a infração for cometida contra o Conselho Federal ou seus membros. O procedimento tramita de forma sigilosa perante o TED da seccional, com os documentos instruídos na subseção ou por relatores da seccional.

Dessa decisão poderão ser interpostos recursos, sendo recorríveis apenas as decisões terminativas, de mérito ou não, não havendo previsão de recursos contra decisões interlocutórias. Das decisões proferidas, a OAB/PR disponibiliza apenas o ementário, não sendo possível verificar o inteiro teor do julgamento, vez que é sigiloso.

Os julgados do Tribunal de Ética e Disciplina da OAB/PR são escassos, apresentam poucas punições sobre atividades advocatícias no ambiente virtual, e, quando elas existem, são muito brandas - a maior parte dos 125 julgados disponíveis para o resultado de pesquisa "publicidade" tratam de questões físicas, como panfletagem e participação em rádios comunitárias e envio de brindes e

convocações.

Em visita realizada junto ao ementário do Tribunal Disciplinar Paranaense, esta pesquisa constatou haver apenas sete julgados relacionados ao tema internet, sendo dois referentes à rede social Facebook, igual número em relação à mala-direta e aos anúncios comuns na internet, e um julgado acerca de publicação realizada no extinto ORKUT.

Referente à publicidade veiculada no facebook temos:

\begin{abstract}
REPRESENTAÇÃO DISCIPLINAR ADVOGADOS QUE FAZEM PUBLICIDADE EM REDE SOCIAL (FACEBOOK), SEM INFORMAÇÃO DAS INSCRIÇÕES NA OAB, ASSIM COMO REALIZANDO AUTOENGRANDECIMENTO, QUALIDADE DE SERVIÇOS, COM OBJETIVO DE CAPTAR CLIENTELA. PUBLICIDADE SEM MODERAÇÃO DE CONTEÚDO. INFRAÇÕES DISCIPLINARES CARACTERIZADAS - PROCEDÊNCIA DA REPRESENTAÇÃO - Advogados que fazem publicação emrede social (facebook), sem informar suas inscrições na $O A B$, oferecendo serviços profissionais sem moderação, com objetivo de captação de clientela, publicando textos jurídicos vedados pelas normas do Código de Ética, do Estatuto e do Provimento 94/2000, praticam infrações disciplinares previstas no inciso IV, do artigo 34, do EOAB, assim como dos artigos 7, 28 e 29 do Código de Ética e Disciplina e do Provimento 94/2000, do Conselho Federal da OAB. Representação Procedente. PENA DE CENSURA, convertida em advertência em oficio reservado, ante existência de atenuantes. (TED - Turma não informada, $\mathrm{N}^{\circ}$ do acórdão: $24911 / 2015, \mathrm{n}^{\circ}$ do processo: 4482/2014, Relator: André Delanhol, Data de Julgamento: 14/08/2015).
\end{abstract}

Diante a ementa supracitada, tem-se o caso de gravíssima violação ao Código de Ética e Disciplina e ao Estatuto da OAB. Na ocasião, o profissional acabou por fazer propaganda de forma desmedida em seu perfil na rede social. Não observou quaisquer parâmetros ou regras. Apesar de reconhecer tais irregularidades, a punição imposta pelo Tribunal de Ética não conduz ao atendimento de uma das funções da punição: seu caráter pedagógico.

O caráter pedagógico da norma está em 
punir de forma exemplar e reprimir a reiteração de condutas similares por parte tanto do punido quanto de seus pares.

Noutra situação levada ao TED da OAB/PR, abordou-se a captação de clientela por meio da publicidade enviada via mala-direta, incorrendo em oferta dos serviços profissionais via e-mail. Uma clara demonstração de pouco ou nenhum temor quanto à punição que pudesse sofrer caso fosse representado perante os mecanismos de controle da $O A B$, senão vejamos:

PUBLICIDADE - ANÚNCIO VIA MALA DIRETA - IMODERAÇÃO - CAPTAÇÃO DE CLIENTELA - Anuncia via internet mala direta - de serviços profissionais. Fato comprovado. Vedação. Infração aos arts. 28 e 29 do CED e letras "e" e "i" do provimento 94/2000 do Conselho Federal da OAB. Procedência de Representação. Decisão unânime. (TED - Turma não informada, $\mathrm{N}^{\circ}$ do acórdão: $10013 / 2007, \mathrm{n}^{\circ}$ do processo: 1583/2007, Relator: Robinson Elvis Kades de Oliveira e Silva, Data de Julgamento: 13/12/2007).

De acordo com o entendimento do Tribunal de Ética e Disciplina, o advogado que utiliza de anúncio via mala direta - envio de e-mails pautados em seus serviços profissionais - comete infração ao objetivo da publicidade jurídica que é de ser exclusivamente informativa.

Dentre os casos analisados no ementário, a sanção mais gravosa foi proferida no processo $\mathrm{n}^{\circ}$. 1661/2010, que impôs 120 dias de suspenção por envio de mala-direta (OAB-PR, 2014). As demais punições foram penas de censura convertidas em advertência, denotando-se o quão pífio é o sistema punitivo a quem pratica a advocacia, contrariamente aos preceitos éticos. Segue abaixo o julgado supracitado:

$\begin{array}{lrr}\text { REPRESENTAÇÃO } & \text { - MALA DIRETA } \\ \text { - CORRESPONDENCIA } & \text { CIRCULAR } \\ \text { USO DA INTERNET } & \text { CONTEUDO } \\ \text { MARCADAMENTE } & \text { PERSUASIVO } \\ \text { - ANGARIAÇÃO } & \text { DE } & \text { CLIENTELA } \\ \text { DOCUMENTAÇÃO DE } & \text { DUPORTE } \\ \text { PROBATÓRIO - } & \text { CONVENCIMENTO } \\ \text { - PROCEDÊNCIA - REINCIDENCIA - } \\ \text { FUNDAMENTO PARA APLICAÇÃO DO } \\ \text { ART } 37 \text { INC. } 11 \text { - SUSPENSÃO POR } 120 \\ \text { DIAS. (TED - Turma não informada, N }\end{array}$

do acórdão: $23796 / 2014, \mathrm{n}^{\circ}$ do processo: 1661/2010, Relator: Fabio Ciuffi, Data de Julgamento: 16/09/2014).

Ante a punição supracitada ser a maior encontrada no ementário da OAB/PR, indaga-se o motivo de tão poucos julgados sobre publicidade digital e o motivo de punições tão brandas.

\section{CONSIDERAÇÕES FINAIS}

Ante o exposto neste estudo, pode-se concluir que o bom exercício da advocacia nos meios digitais deve estar em consonância com os preceitos éticos do Código de Ética e Disciplina da Ordem dos Advogados do Brasil. Contudo, o que se pode observar nesta pesquisa, foi que a atuação do advogado nos meios digitais transpõe os limites impostos.

Nessa acepção, embora o CED seja tido como obsoleto e, omisso quanto ao tema internet, é possível denotar que os mecanismos atuais utilizados pelo advogado são tão lesivos aos preceitos deontológicos quanto os descritos no referido Código. Mecanismos, estes, fomentados por impulsionamentos pagos ou plataformas que fazem a ponte entre um possível cliente e o advogado, com um intuito que foge do caráter informativo e da moderação. Culminando, assim, na mercantilização da profissão e na captação de clientela.

Tais condutas lesivas aos princípios éticos, no decorrer do trabalho, mostraram-se ordinárias. E os julgados do Tribunal de Ética e Disciplina da OAB/PR sobre o tema "publicidade", com foco nos meios digitais, restaram escassos e sem maiores detalhamentos. Não obstante, as sanções impostas não se mostram suficientes para restringir atuações tendenciosas de advogados na internet e, nem para impor efetivo caráter pedagógico aos demais profissionais, sobretudo quando se emitem punições brandas aos infratores.

\section{REFERÊNCIAS}

BRASIL. Constituição (1988). Constituição da República Federativa do Brasil: promulgada em 8 de outubro de 1988. Brasília, Senado, 1988.

BRASIL. Lei $n^{\circ} 8.906$ de 4 de julho de 1994 . 
Estatuto da Advocacia e a Ordem dos Advogados do Brasil (OAB). Disponível em: http://www.planalto. gov.br/ccivil_03/Leis/L8906.htm. Acesso em: 16 jul. 2019.

CONSELHO FEDERAL DA OAB. Provimento $\mathbf{n}^{\circ}$ 94/2000 de 5 de setembro de 2000. Dispõe sobre a publicidade, a propaganda e a informação da advocacia. Disponível em: https://www.oab.org. br/leisnormas/legislacao/provimentos/94-2000. Acesso em: 16 jul. 2019.

CONSELHO FEDERAL DA OAB. Resolução n. ${ }^{\circ}$ 2 de 19 de outubro de 2015. Aprova o Código de Ética e Disciplina da Ordem dos Advogados do Brasil - OAB. Disponível em: https://www.oab. org.br/visualizador/19/codigo-de-etica-e-disciplina. Acesso em: 14 jun. 2018.

COSTA, T. Quais são as redes sociais mais usadas no país? 2018. Disponível em: https:// marketingdeconteudo.com/redes-sociais-maisusadas-no-brasil/. Acesso em: 10 jun. 2018.

COUTURE, E. J. Os mandamentos do advogado. Porto Alegre: Fabris, 1979.

DINO. Revista EXAME. Investimento em marketing digital tem previsão de crescer $12 \%$ ao ano até 2021, segundo pesquisa. 22 nov. 2018. Disponível em: https://exame.abril.com.br/ negocios/dino/investimento-em-marketing-digitaltem-previsao-de-crescer-12-ao-ano-ate-2021segundo-pesquisal. Acesso em: 20 jul. 2019.

GESENHUES, A. Marketing Land. Report: Facebook takes a back seat to Instagram as ad spend on the Facebook-owned app grows $177 \%$. Publicado em 24 de julho de 2018. Disponível em: https://marketingland.com/report-facebook-takesa-back-seat-to-instagram-as-ad-spend-on-thefacebook-owned-app-grows-177-244893. Acesso em: 10 jul. 2019.

LÔBO, P. Comentários ao Estatuto da Advocacia e da OAB. 7. ed. São Paulo, SP: Saraiva, 2012.

KELSEN, H. Teoria pura do direito. 6. ed. Martins Fontes: São Paulo, 1999.
KEMP, S. Digital in 2017: global overview. Disponível em: https://wearesocial.com/specialreports/digital-in-2017-global-overview. Acesso em: 11 jun. 2018.

OAB PARANÁ. Resolução do Conselho Seccional $n^{\circ}$ 20/2018 de 07 de dezembro de 2018. Dispõe sobre a tabela de honorários e documentos correlatos compilados. Disponível em: https://honorarios.oabpr.org.br/wp-content/ uploads/2019/01/20191207-tabela-de-honorariosresolucao-20-2018.pdf. Acesso em: 16 jul. 2019.

OAB PARANÁ. Ética e disciplina. Câmara de disciplina. Acórdãos. Ementário sobre o tema: publicidade. Disponível em: http://intranet.oabpr. org.br/servicos/ementario/ementario2.asp. Acesso em: 14 jul. 2019.

VIEIRA, T. R.; MARTINS, J. P. N. P. Ética no direito. Petrópolis: Vozes, 2007.

\section{ÉTICA EN ABOGACÍA Y MUNDO DIGITAL: DESAFÍOS PARA EL ABOGADO 4.0}

RESUMEN: El artículo buscará plantear interrogantes sobre el desempeño de la actuación del abogado en los medios digitales y sus implicaciones en relación con el Código de Ética y Disciplina de la OAB (Resolución CFOAB n ${ }^{\circ}$ 2/2015) y el Estatuto de Categoría (Ley ${ }^{\circ}$ 8906/94). Dichos mecanismos sirven como parámetro ético y orientan la actividad en abogacía. En ese sentido, se investigó los principales mecanismos que utilizan los abogados en el ámbito digital, considerando sus implicaciones en el ámbito ético de dicha profesión. De primero, se analizó la vigencia del impulso remunerado de publicaciones en redes sociales y la participación del abogado en las plataformas de registro, difusión y captación de clientes. En un segundo paso, se buscó la jurisprudencia de la OAB Paraná, para los resultados de la investigación "publicitaria", con énfasis en los medios digitales. Estableciendo al final una conclusión sobre lo que se considera saludable para el buen ejercicio de la abogacía digital.

Palabras clave: Código de Ética y Disciplina de la OAB; Abogacía digital; Límites éticos; Estatuto de la OAB; Tribunal de Ética y Disciplina de la OAB Paraná. 